THE EFFICACY OF ELECTROMYOGRAPHIC BIOFEEDBACK ON PAIN, FUNCTION AND MAXIMAL THICKNESS OF VASTUS MEDIALIS OBLIQUE MUSCLE IN PATIENTS WITH KNEE OA; A RANDOMISED CLINICAL TRIAL

L. Sedighipour ${ }^{1}$, S.A. Raeissadat ${ }^{1}$, S.M. Rayegani ${ }^{2}$, Z. Bossaghzadeh ${ }^{1}$, M. H. Abdollahzadeh ${ }^{1}$, F. Malayi ${ }^{3}{ }^{1}{ }^{1}$ Physical Medicine and Rehabilitation, Modarres hospital; ${ }^{2}$ Tajrish square; ${ }^{3}$ Physical Medicine and Rehabilitation, Shohada hospital, Tehran, Iran, Islamic Republic of Ireland

Background: Isometric exercises play important role in treatment of Knee OA and are easy to do by the growing elderly population. Electromyographic (EMG) biofeedback devices are designed to enhance patient's participation in these exercises by giving them feedback signals of visual or auditory nature, so that it can affect the subject's voluntary activity.

Objectives: The aim of this survey was to study the effect of EMG biofeedback on pain, function, thickness of the vastus medialis oblique muscle and maximal electrical activity of this muscle in isometric contraction, in patients with knee OA. Methods: In this single-blinded clinical trial, 46 patients aged between 45 to 70 , referring to Shohadaye Tajrish and Shahid Modarres hospitals with diagnosis of knee OA, were recruited. Patients were randomlyassigned to two groups of case (23 patients), with EMG biofeedback associatedexercise, and control (23 patients), with sham biofeedback associatedexercise. The exercise program includes 12 sessions of $15 \mathrm{~min}$ isometric quadriceps exercise. Data were gathered via VAS score, the Persian version of WOMAC and Lequesne questionnaires, ultrasonography of VMO muscle and surface electromyography of this muscleat baseline and at the end of 2 months period of this study. Variables compared before and after exercises program in each group and between the two groups.

Results: At the end of the study, there were no significant differences between the two groups regarding VAS score, VMO muscle electrical activity, maximal VMO muscle thickness, WOMAC and Lequesne questionnaires scores including overall scores and scores in each subcategories. Although all assessed parameters, except for VMO muscle thickness, were found to be improved significantly in each group, the changes were not more significant in case group except for the VAS score. VMO muscle thickness didn't change significantly after 12 sessions of exercise in either of the groups.

Conclusions: Isometric exercises accompanied by EMGBF and the same exercises with sham biofeedback for 2 months both lead to significant improvements in pain, and function of patients with knee OA. Real EMG biofeedback was not superior to sham biofeedback. The only parameter found to be improved to a greater extent in the EMGBF group was the subjective measure of VAS score.

Disclosure of Interest: None declared

DOI: 10.1136/annrheumdis-2018-eular.5069

\section{AB0974 \\ THE EFFICACY AND SAFETY OF INTRA-ARTICULAR BOTULINUM TOXIN INJECTION IN KNEE OSTEOARTHRITIS}

S.M. Rayegani ${ }^{1}$, S.A. Raeissadat ${ }^{2}$, E. Enayati ${ }^{1}$, S. Rahimi Dehgolan ${ }^{1,1} .{ }^{1}$ Physical Medicine and Rehabilitation, Shohada-e-Tajrish Hospital, Shahid Beheshti University of Medical Sciences, Tehran, Iran; ${ }^{2}$ Physical Medicine and Rehabilitation, Clinical Development Research Center of Shahid Modarres Hospital, Physical Medicine and Rehabilitation Research Center, Shahid Beheshti University of Medical Sciences, Tehran, Iran, Islamic Republic of Ireland

Background: Osteoarthritis $(\mathrm{OA})$ is a common disease that has a great burden through pain and decreased functional capacity. Botulinum toxin-A (BTA) injection has been recently proposed for knee OA patients to reduce pain and disability.

Objectives: In this study we evaluate BTA injection efficacy and safety among non-advance knee OA participants in a before-after trial.

Methods: This trial was conducted on knee OA patients presented to our PM and $R$ clinic. Thirty participants aged $40-75$ years who had radiographic OA grades of II and III KLS were included. Single intra articular injection of half of a $500^{\prime \mathrm{U}}$ vial BTA was applied for all participants. Patients were prospectively evaluated at baseline and then at 8 and 24 weeks after injection using the visual analogue scale (VAS) for pain and Western Ontario and McMaster Universities Osteoarthritis Index (WOMAC) in three subscales: pain, stiffness and function.

Results: Both main outcome measures of this trial (VAS and WOMAC) significantly improved after 24 weeks follow up. About two third of final VAS improvement was achieved in the first week after injection (from 7.2 to $4.5, M D \%=36 \%$, p value $=0.008$ ); then at 8 and 24 weeks post injection VAS reached 3.8 and 3.3 , respectively. Almost $81 \%-77 \%$ of patients had more than $30 \%$ decline in their baseline VAS at 8th and 24th week visits, respectively. Also a similar pattern was observed for WOMAC index of sixth month (from 56.7 to 31.0, Mean Difference $=-25.7[\mathrm{MD} \%=45 \%]$, $p$ value $=0.005$ ), with more remarkable changes in function subscale $(\mathrm{MD} \%=46 \%)$. In this study no major adverse events were noted.

\begin{tabular}{lcccc}
\hline Measure & Before & After & Mean Diff (SD) & P value \\
& & & & \\
WOMAC & $10.62(3.31)$ & $6.00(1.78)$ & $4.62(2.35)$ & 0.000 \\
$\underline{\text { Pain }}$ & & & & \\
\hline WOMAC & $5.08(1.41)$ & $2.85(1.19)$ & $2.23(0.90)$ & 0.000 \\
$\underline{\text { Stiffness }}$ & & & & \\
\hline WOMAC & $41.08(9.52)$ & $22.15(4.83)$ & $18.92(7.88)$ & 0.000 \\
Function & & & & \\
\hline WOMAC & $56.77(13.03)$ & $31.00(6.96)$ & $25.7(10.22)$ & 0.000
\end{tabular}

Total

Abstract AB0974 - Figure 1

Conclusions: BTA showed promising effects in improving knee pain, ROM and functional status. Therefore this single session method could be considered as an alternative to other intra articular injections in knee OA patients who did not response to preliminary conservative treatments. Further data is necessary to assess long-term effects and cost-benefit analysis of BTA against other similar choices.

Disclosure of Interest: None declared

DOI: 10.1136/annrheumdis-2018-eular.5281

\section{AB0975 DOES PLATELET RICH PLASMA CHANGE THE VOLUMETRIC FINDINGS OF MRI IMAGING? (A RANDOMISED CLINICAL TRIAL)}

S.A. Raeissadat ${ }^{1}$, E. Ghorbani ${ }^{1}$, M. Sanei ${ }^{2}$, S.M. Rayegani ${ }^{1}$, M. Babaee ${ }^{1}$, R. Soleimani ${ }^{2} .{ }^{1}$ PHYSICAL MEDICINE AND REHABILITATION RESEARCH CENTER, SHAHID BEHESHTI UNIVERSITY OF MEDICAL SCIENCES;

${ }^{2}$ Radiology Department, Shahid Beheshti university of medical sciences, Tehran, Iran, Islamic Republic of Ireland

Background: Several studies have shown the effect of platelet rich plasma (PRP) on knee osteoarthritis. Most of these studies have focused on subjective and clinical symptoms effect of PRP and fewer papers have studied its objective effect on cartilage. MRI is the gold standard imaging for cartilage lesion.

Objectives: In this study, we investigated the effect of PRP on cartilage characteristics by special MRI sequencing.

Methods: In the double blind randomised clinical trial, patients with grade1, 2 and 3 of osteoarthritis were included in this study. All of the knees divided to groups randomly and exercise was prescribed for all of knees. Beside, PRP was injected 2 courses with 4 weeks interval in PRP group. For all of patients before and 6 months after treatment VAS (visual analogue scale) and WOMAC (Western Ontario and McMaster Universities Arthritis Index) were fulfilled and MRI was performed. Sequencings of MRI were PD fat saturated (coronal and sagittal) and transverse TRUFISP 3D. Imaging was scored according to 4 cartilage's characteristics including, Patellofemoral cartilage volume, Subarticular bone marrow abnormality, Medial and lateral meniscal disintegrity and Synovitis.

Results: 23 knees in case group and 23 knees in control group were studied. All of patients were female with mean age $57.57 \pm 5.9$ years old and mean BMI 28.49 $\pm 3.24\left(\mathrm{Kg} / \mathrm{m}^{2}\right) .52 \%$ of knees had grade 2 of osteoarthritis. Mean total WOMAC and VAS changes before and after treatment in control group were $11.61 \pm 1.3$ and $8.5 \pm 1.1$ respectively. In PRP group, mean total of WOMAC and VAS changes showed better improvement with $20 \pm 3.2$ and $12.3 \pm 1.6$ respectively $(P$ Value $<0.05)$. In PRP group all of the radiologic variables except subarticular bone marrow abnormality had significantly improvement $(P$-Value $<0.05)$. In comparison between 2 groups, Patellofemoral cartilage volume and synovitis had significantly changes in PRP group (P-Value $<0.05)$.

Conclusions: In this study, in addition to the effect of PRP on VAS and WOMAC there is effect on radiologic characteristics (Patellofemoral cartilage volume and synovitis) significantly. For more evaluation, Study with more sample size is recommended.

\section{REFERENCES}

[1] Raeissadat SA, Babaee M, Rayegani SM, Hashemi Z, Hamidieh AA, Mojgani $P$, et al. An overview of platelet products (PRP, PRGF, PRF, etc.) in the Iranian studies. Future science OA. 2017;3(4):FSO231.

[2] Raeissadat SA, Rayegani SM, Ahangar AG, Abadi PH, Mojgani P, Ahangar OG. Efficacy of Intra-articular Injection of a Newly Developed Plasma Rich in Growth Factor (PRGF) Versus Hyaluronic Acid on Pain and Function of Patients with Knee Osteoarthritis: A Single-Blinded Randomized 
Clinical Trial. Clinical Medicine Insights: Arthritis and Musculoskeletal Disorders. 2017:10:1179544117733452.

[3] Raeissadat SA, Rayegani SM, Hassanabadi H, Fathi M, Ghorbani E, Babaee M, et al. Knee osteoarthritis injection choices: platelet-rich plasma (PRP) versus hyaluronic acid (a one-year randomized clinical trial). Clinical Medicine Insights: Arthritis and Musculoskeletal Disorders. 2015;8: CMAMD. S17894.

[4] Raeissadat SA, Rayegani SM, Moridnia M, Dehgolan SR. AB1246-HPR Intra articular ozone or hyaluronic acid injection: which one is superior in patients with knee osteoarthritis? a 6-month randomized clinical trial. BMJ Publishing Group Ltd; 2017.

Disclosure of Interest: None declared DOI: 10.1136/annrheumdis-2018-eular.7211

\section{AB0976 EFFICACY OF INTRA-ARTICULAR INJECTION OF PRP- DRIVED GROWTH FACTOR (PRP WITHOUT PLATELET AND WBC) VERSUS HYALURONIC ACID ON PAIN AND FUNCTION OF PATIENTS WITH KNEE OSTEOARTHRITIS: A SINGLE-BLINDED RANDOMISED CLINICAL TRIAL}

S.A. Raeissadat, A. gharooee ahangar, S.M. Rayegani. physical medicine and rehabilitation, shahid beheshti university of medical science, tehran, Iran, Islamic Republic of Ireland

Background: Knee osteoarthritis is the most common joint disease.

Objectives: We aimed to compare the efficacy and safety of intra-articular injection of PRP-drived growth factor versus hyaluronic acid (HA) on pain and function of patients with knee osteoarthritis.

Methods: In this single-blinded randomised clinical trial, patients with symptomatic osteoarthritis of knee were assigned to receive 2 intra-articular injections of PRP-drived growth factor in 3 weeks or 3 weekly injections of HA. Our primary outcome was the mean change from baseline until 2 and 6 months post intervention in scores of visual analogue scale, Western Ontario and McMaster Universities Osteoarthritis Index (WOMAC), and Lequesne index.

Results: A total of 69 patients entered final analysis. The mean age of patients was $58.2 \pm 7.41$ years and $81.2 \%$ were women. Total WOMAC index decreased from $42.9 \pm 13.51$ to $26.8 \pm 13.45$ and $24.4 \pm 16.54$ at 2 and 6 months in the PRGF group (within subjects $p=0.001$ ), and from $38.8 \pm 12.62$ to $27.8 \pm 11.01$ and $27.4 \pm 11.38$ at 2 and 6 months in the HA group (within subjects $p=0.001$ ), respectively (between subjects $p=0.631$ ). There was no significant difference between PRP-drived growth factor and HA groups in patients' satisfaction and minor complications of injection, whereas patients in HA group reported significantly lower injection-induced pain.

Abstract AB0976 - Table 1

\begin{tabular}{|c|c|c|c|c|c|c|}
\hline \multicolumn{6}{|c|}{ WOMAC scores } & \multirow[t]{2}{*}{ VAS } \\
\hline & & Pain & Function & Stiffness & Total & \\
\hline \multirow[t]{5}{*}{ PRGF } & Baseline & $9.2 \pm 2.97$ & $\begin{array}{c}30.6 \\
\pm 10.09\end{array}$ & $3.0 \pm 2.01$ & $\begin{array}{c}42.9 \\
\pm 13.51\end{array}$ & $7.8 \pm 1.78$ \\
\hline & At 2 month & $5.8 \pm 2.96$ & $19.5 \pm 9.79$ & $1.6 \pm 1.66$ & $\begin{array}{c}26.8 \\
\pm 13.45\end{array}$ & $4.9 \pm 2.21$ \\
\hline & At 6 month & $5.3 \pm 3.60$ & $\begin{array}{c}17.6 \\
\pm 11.70\end{array}$ & $1.5 \pm 1.84$ & $\begin{array}{c}24.4 \\
\pm 16.54\end{array}$ & $4.6 \pm 2.78$ \\
\hline & $\begin{array}{l}P \text { value within } \\
\text { groups }\end{array}$ & 0.0001 & 0.0001 & 0.0001 & 0.0001 & 0.0001 \\
\hline & Hyalgan & Baseline & $8.7 \pm 3.01$ & $\begin{array}{r}27.8 \\
\pm 9.62 \\
\end{array}$ & $2.3 \pm 1.64$ & $\begin{array}{c}38.8 \\
\pm 12.62 \\
\end{array}$ \\
\hline
\end{tabular}

$7.4 \pm 1.48$

At 2 month

$5.9 \pm 2.65$

$20.6 \pm 8.04$

$1.2 \pm 1.39$

$27.8 \pm 11.01$

$4.8 \pm 1.80$

At 6 month

$5.9 \pm 2.79$

$20.1 \pm 7.77$

$1.3 \pm 1.48$

$27.4 \pm 11.38$

$4.8 \pm 2.39$

$P$ value within groups

0.0001
0.0001

0.0001

0.0001

0.0001

$P$ value Between Groups

0.847

0.894

0.189

0.985

0.648
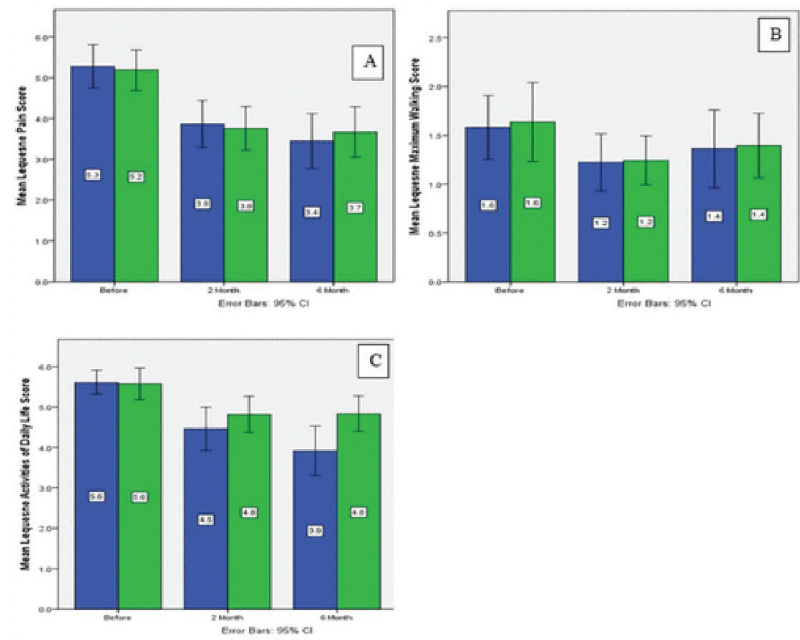

Abstract AB0976 - Figure 1

Conclusions: In 6 months follow up, PRP-drived growth factor and HA, both are effective options to decrease pain and improvement of function in patients with mild to moderate knee osteoarthritis.

\section{REFERENCES}

[1] Raeissadat, SA, Babaee, M, Rayegani, SM. An overview of platelet prod ucts (PRP, PRGF, PRF, etc.) in the Iranian studies [published online ahead of print July 28, 2017]. Futur Sci OA. doi:10.4155/fsoa-2017-0045.

[2] Raeissadat, SA, Rayegani, SM, Babaee, M, Ghorbani, E. The effect of platelet-rich plasma on pain, function, and quality of life of patients with knee osteoarthritis. Pain Res Treat. 2013;2013:165967. Google Scholar

[3] Raeissadat, SA, Rayegani, SM, Hassanabadi, H. Knee osteoarthritis injection choices: platelet-rich plasma (PRP) versus hyaluronic acid (a one-year randomized clinical trial). Clin Med Insights Arthritis Musculoskelet Disord. 2015;8:1-8.

[4] Raeissadat SA, Rayegani SM, Moridnia M, Dehgolan SR. Intra articula ozone or hyaluronic acid injection: which one is superior in patients with knee osteoarthritis? a 6-month randomized clinical trial.Annals of the Rheumatic Diseases 2017;76(Suppl 2):1547-1548.

Disclosure of Interest: None declared

DOI: 10.1136/annrheumdis-2018-eular.3701

\section{AB0977 CORRELATION OF THE LEVEL OF C-REACTIVE PROTEIN AND BONE MINERAL DENSITY IN PATIENTS WITH GONARTHRITIS}

T. Tarasenko. Polyclinic, Regional Clinical Hospital named after I.I. Mechnikov, Dnipro, Ukraine

Background: The results of recent studies also indicate a link between loss of bone mineral density (BMD) and progressive loss of articular cartilage in patients with knee joint osteoarthritis $(\mathrm{OA})$. The presence of correlation of changes in bone tissue and degradation of cartilage in $\mathrm{OA}$ is due to the possible presence of common pathogenesis chains, including activation of proinflammatory mediators.

Objectives: Determine the relationship between the level of $\mathrm{C}$-reactive protein (CRP) and the level of BMD in patients with gonarthritis.

Methods: We conducted a cross sectional study including confirmed radiographic knee osteoarthritis according to Kellgren-Lawrence scale, with norma and reduced BMD according to the classification of Report of a WHO Study Group. The structural and functional status of bone tissue in patients was 